\title{
METABOLIC STUDIES IN PARALYTIC ACUTE ANTERIOR POLIOMYELITIS. II. ALTERATIONS IN CALCIUM AND PHOSPHORUS METABOLISM ${ }^{1}$
}

\author{
By G. DONALD WHEDON ${ }^{2}$ AND EPHRAIM SHORR $\dagger$ \\ WITH THE TECHNICAL ASSISTANCE \\ of VINCENT TOSCANI AND ESTELLE STEVENS
}

\begin{abstract}
(From the Russell Sage Institute of Pathology, the Department of Medicine, Cornell University Medical College, and the New York Hospital, New York, N. Y.)
\end{abstract}

(Submitted for publication July 27, 1956; accepted November 26, 1956)

Further evidence of the extensive effects of infection with the poliomyelitis virus upon many bodily systems is presented in this paper, the second of a series (1) describing metabolic and physiological features of the natural course of paralytic acute anterior poliomyelitis during its acute, convalescent and chronic phases.

The most marked alteration in metabolism noted during the immobilization of healthy subjects in body casts (2) was greatly increased excretion of calcium, progressing to urinary calcium outputs more than double those of the control phase and to large negative calcium balances. This striking result suggested that it would be pertinent to investigate the extent of mineral loss occurring in patients with a seriously immobilizing disease such as paralytic acute anterior poliomyelitis.

Several indications of alteration in calcium and phosphorus metabolism in poliomyelitis have been reported, such as hypercalcemia, hypercalciuria, urinary tract lithiasis, bone rarefaction and retardation of bone growth. Orr (3) found hypercalcemia four months after onset in a nine-yearold boy with extensive paralysis and, later, in 10 of 11 other children with paralytic poliomyelitis. Wilkins (4) noted "hypercalcemia in some of the paralytic cases at Children's Hospital" in Baltimore. Hypercalciuria in poliomyelitis has been mentioned several times but quantitatively only once, by Wilkins (5) who found as much as 1 gram per day in the urine of a patient, presumably a child, with poliomyelitis. The frequence of urinary tract calculi formation in poliomyelitis is well known, particularly in severely paralyzed patients

\footnotetext{
1 Aided by a grant from the National Foundation for Infantile Paralysis.

2 Present Address: National Institute of Arthritis and Metabolic Diseases, National Institutes of Health, Bethesda, Maryland.

† Died, January 6, 1956.
}

restricted to respirators $(6,7)$, although the precise incidence has not been tabulated. Osteoporosis in paralytic poliomyelitis $(5,8-10)$ has been recognized, but except for our preliminary abstract of these studies (11) accounts have not documented the extent of associated calcium loss. Retardation of bone growth with shortening of the paralyzed limbs of children prior to the age of bone maturity has been shown to be related to the degree of muscle atrophy in the involved extremity and unrelated to the child's age at onset $(12,13)$.

Interest of recent observations of serum alkaline phosphatase in poliomyelitis has been focused not on bone metabolism but on involvement of enzymatic processes in severe infections. Ainslie, Stumpf, and Francis (14) showed a brief fall in alkaline phosphatase in monkeys with paralytic poliomyelitis or malaria and in cows infected with $\mathrm{Br}$. abortus. In 86 humans with poliomyelitis, however, they found no significant lowering during the first two weeks after onset.

The present report outlines the extent and varying pattern of changes in calcium and phosphorus metabolism, principally with respect to the excretion and balance of these elements, during various phases of paralytic poliomyelitis. Particular attention is given to conditions favoring the development of osteoporosis and urinary tract calculi.

\section{PROCEDURE}

Plan and procedure of these studies were outlined in the first paper in the series (1). The present report is based on data of the same nine patients, who were studied for from five to nine months on the Metabolism Ward of the Russell Sage Institute of Pathology and New York Hospital. Study was begun early in the acute phase in four of the nine.

Consecutive metabolic data are given in tables in Appendix A. Paralysis ranged in degree and extent from moderately marked to severe. Detailed case summaries are given in Appendix B. Patients' care and therapy 


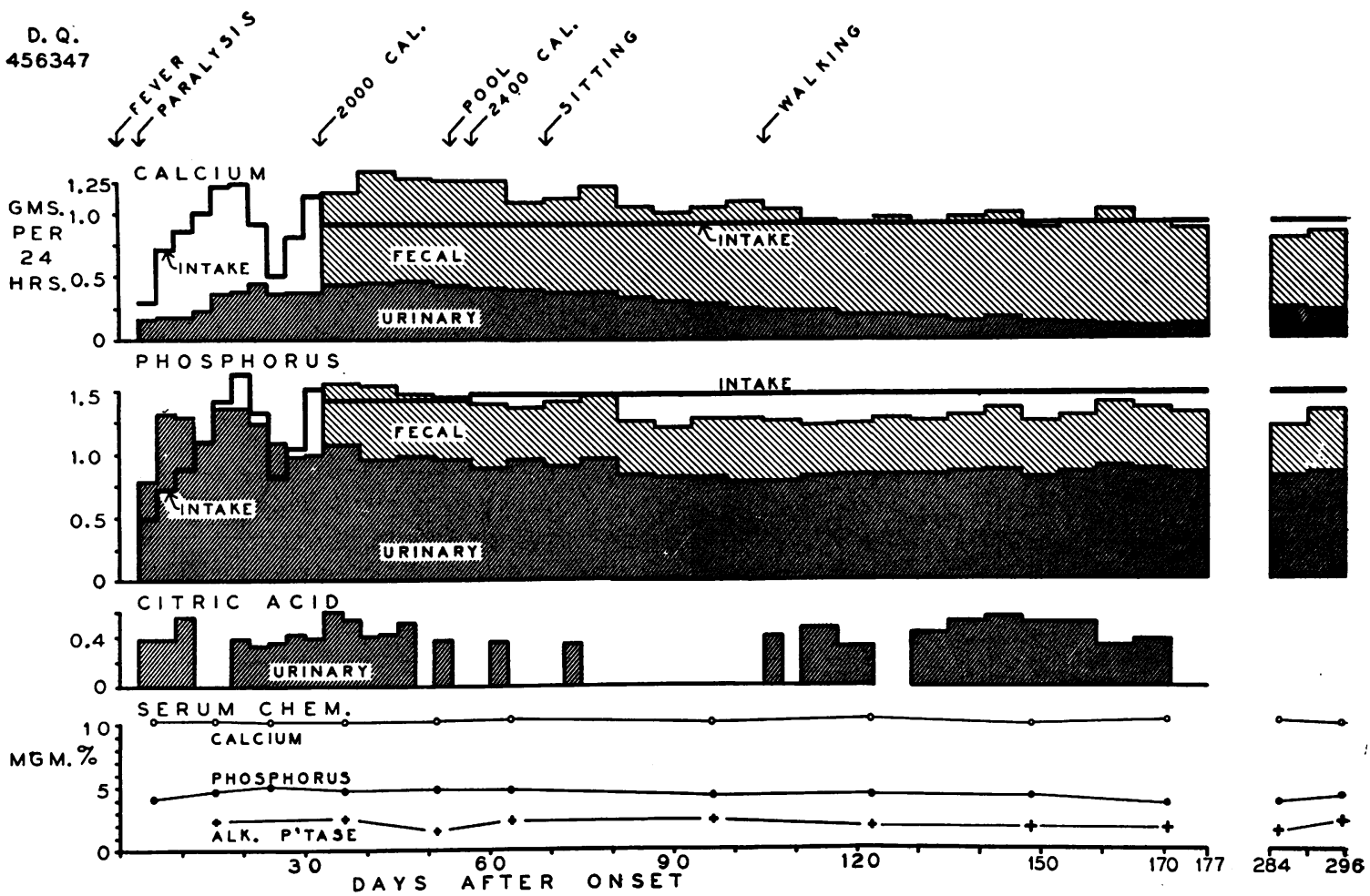

Fig. 1. Calcium and Phosphorus Balances, Urinary Citric Acid and Serum Calcium, Phosphorus and Alkaline Phosphatase During the First Six and Tenth Months of Illness in a 21-year-old Male with Paralytic Acute Anterior Poliomyelitis

Serum alkaline phosphatase is plotted in this and in subsequent graphs in Bodansky units. The balance data in this and in subsequent graphs are charted with the intake and output both plotted upward from the base-line and urinary output on the bottom in order to portray clearly changes in urinary excretion as well as changes in balance.

and the constant diets given throughout the studies were described in the first paper of the series (1).

\section{METHODS}

Routine of the Metabolism Ward has been described $(1,2)$. Balance studies were carried out in six-day periods. Initially, urinary calcium and phosphorus were determined daily, but later their analyses and that of citric acid were made on three-day pooled specimens. Methods of analysis of urine, stool and serum for calcium and phosphorus in this laboratory have been previously stated (2). Urinary citric acid was determined by the method of Taussky and Shorr $(15,16)$. Serum alkaline phosphatase was determined by the method of Bodansky $(17,18)$ as modified by Woodward (19).

\section{RESULTS}

\section{A. Acute and Convalescent Phases}

Data of acute and convalescent phases (first six months) are considered together since, with the exception of shifts in urinary phosphorus, changes were not rapid. Alterations in calcium in particular were gradual and sluggish, extending over several months. The data of seven patients (Figures 1 to 4 ) were used as the basis for the following description.

\section{Calcium}

a. Pattern and degree of loss. Urinary calcium increased gradually to high levels at the fifth week after onset of illness. Among the seven patients maximal urinary calcium ranged between 0.391 and $0.789 \mathrm{gm}$. per day (average over a six-day period), the mean maximum for the group being $0.574 \mathrm{gm}$. per day (Table I). Urinary calcium was maintained at a high plateau, remaining above $0.250 \mathrm{gm}$. per day for an average of five and onehalf months, and declining slowly before ambulation was begun. Fecal calcium excretion was unchanged in four patients and variably increased in three, tending in these latter individuals to be: 


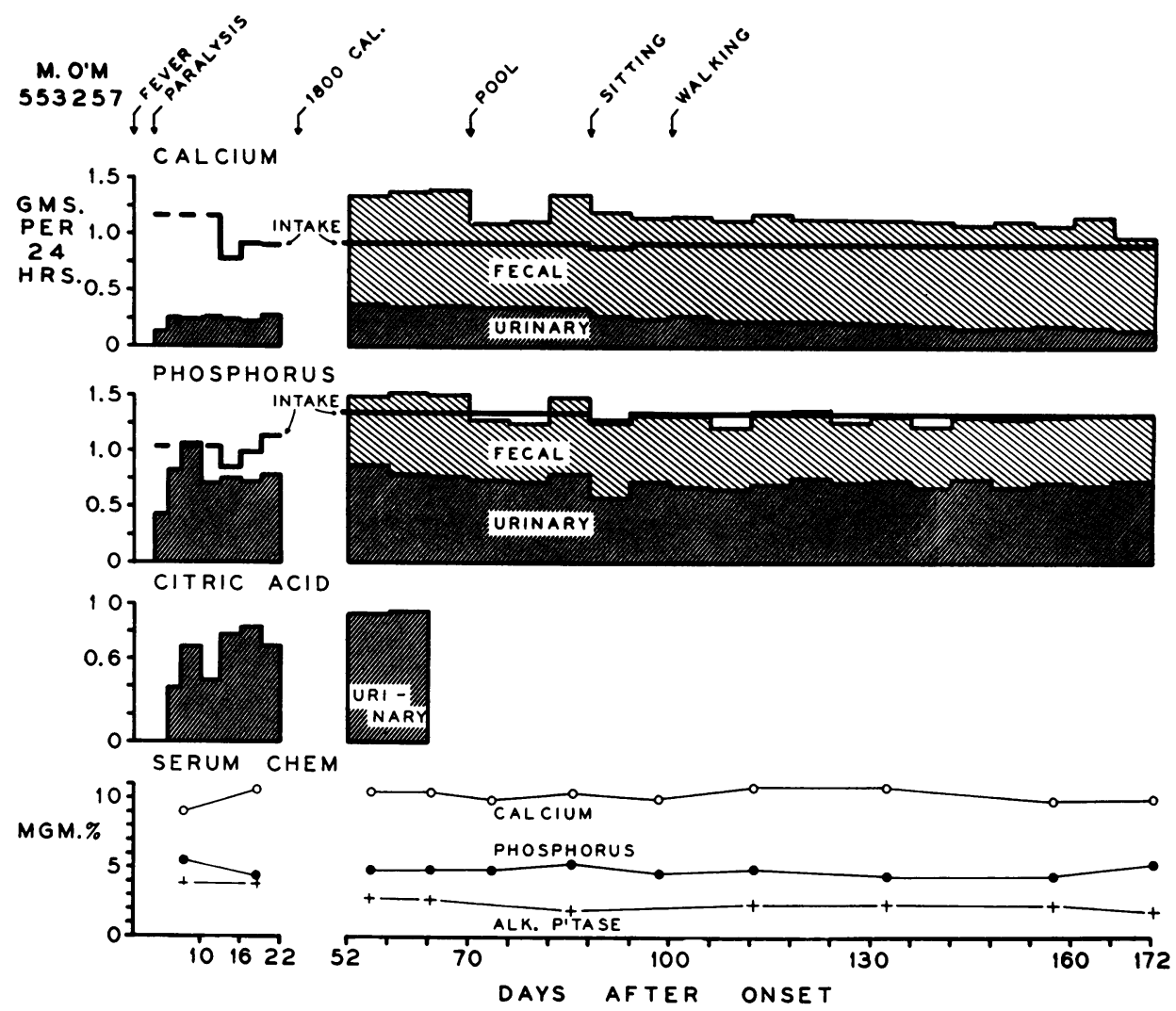

Fig. 2. Calcium and Phosphorus Balances, Urinary Citric Acid Excretion and Serum Calcium, Phosphorus and Alkaline Phosphatase during the First Six Months of Illness in a 21-Year-Old Female with Paralytic Acute Anterior Poliomyelitis

The interruption in this graph and those in subsequent graphs result from the exclusion of data for the periods during and for from two to four weeks following the administration of special procedures (see text).

greatest during the second and third months and remaining within $0.100 \mathrm{gm}$. per day of the calcium intake figure for approximately six months.

Maximal negative calcium balance occurred on the average nine weeks after onset and ranged from -0.420 to $-0.683 \mathrm{gm}$. per day among the seven patients, the mean being $-0.540 \mathrm{gm}$. per day. Negative calcium balance continued for an average of seven months; positive calcium balance was regained approximately one month after patients began to stand on their feet. Average total calcium loss over the seven months was 58 grams.

b. Relation between total loss and osteoporosis. In view of the widely varying estimates of the percentage loss of total body calcium necessary for osteoporosis to become roentgenographically evident and the lack of specific data on this point, analysis in this respect was made of the total cal- cium losses of these patients. In the four patients whose studies were begun within one week of onset the entire loss was exactly measured; in R.W. all but the small losses of the first three weeks were known, and in F.S. all but those of the first four weeks.

$\mathrm{X}$-rays of long bones and spine taken at approximately monthly intervals were evaluated by Dr. John Evans, Radiologist-in-Chief of the New York Hospital-Cornell Medical Center, who was unaware of the metabolic data. Initial $\mathrm{X}$-ray evidence of osteoporosis was usually a patchy demineralization and coarsening of trabecular markings in the lower extremities regional to the joints, most often in the necks or distal ends of the femora. In three patients the first abnormality noted was a sub-metaphyseal band of rarefaction in the distal tibiae (Figure 5). These earliest signs of de- 


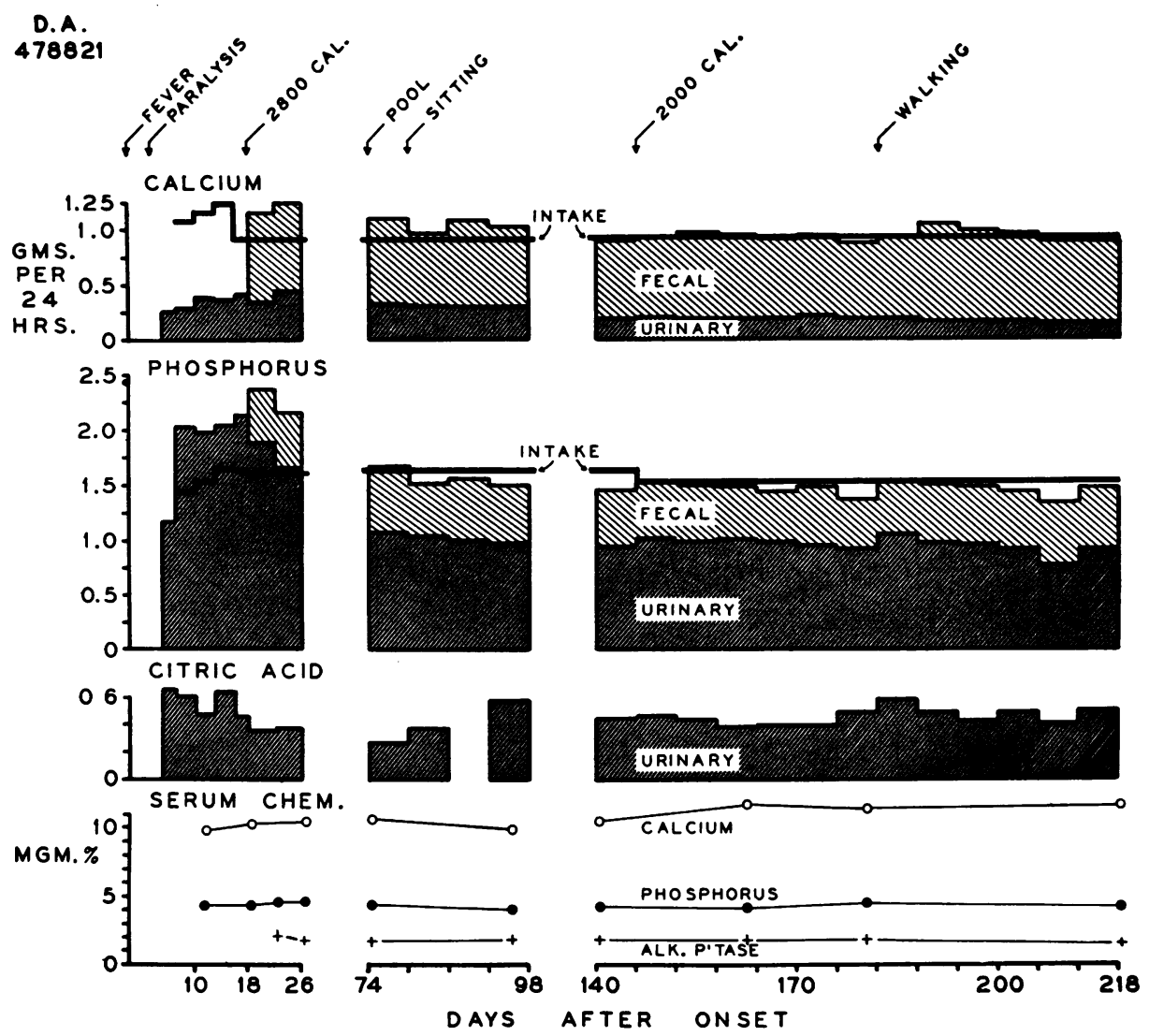

Fig. 3. Calcium and Phosphorus Balances, Urinary Citric Acid Excretion and Serum Calcium, Phosphorus and Alkaline Phosphatase during the First, Third, and Fifth Through Seventh Months of Illness in a 27-Year-Old Male with Paralytic Acute Anterior Poliomyelitis

mineralization appeared approximately three months after onset and occurred with an average loss of 2.0 per cent of the total body calcium. [In Table II in which these data are presented, estimated total body calcium has been taken as 1.8 per cent of pre-illness body weight (20).]

As immobilization continued, areas first noted became more lucent and changes appeared in pubic and ischial rami and in the acetabular fossa of the innominate bone (Figure 6). Although recumbency continued for an average of 6 months, negative calcium balance for 7 months, and total calcium losses averaged 4.6 per cent with range to 9.4 per cent, no changes in the spine could be detected.

\section{Phosphorus}

In contrast to the gradual increase in calcium excretion, phosphorus excretion rose promptly, the increase being entirely in the urinary component. Peak excretion occurred between the 9 th and 17 th days among the four patients studied early, the mean being the 14th day. This was two days prior to the mean day of peak nitrogen excretion and approximately three weeks before maximal calcium output developed.

Maximal urinary phosphorus ranged between 1.07 and $2.13 \mathrm{gm}$. per day (three-day average) with a mean maximum of $1.64 \mathrm{gm}$. per day for patients D.Q., M.O'M., D.A., and J.C. Maximal negative balance, at this same time, using in calculations the average fecal phosphorus over the first four periods, ranged from -0.452 to -0.986 gm. per day, the mean being $-0.724 \mathrm{gm}$. per day. Following this early peak, urinary phosphorus excretion declined gradually but remained more than $1.0 \mathrm{gm}$. per day for an average of three and onehalf months. Return to positive phosphorus bal- 


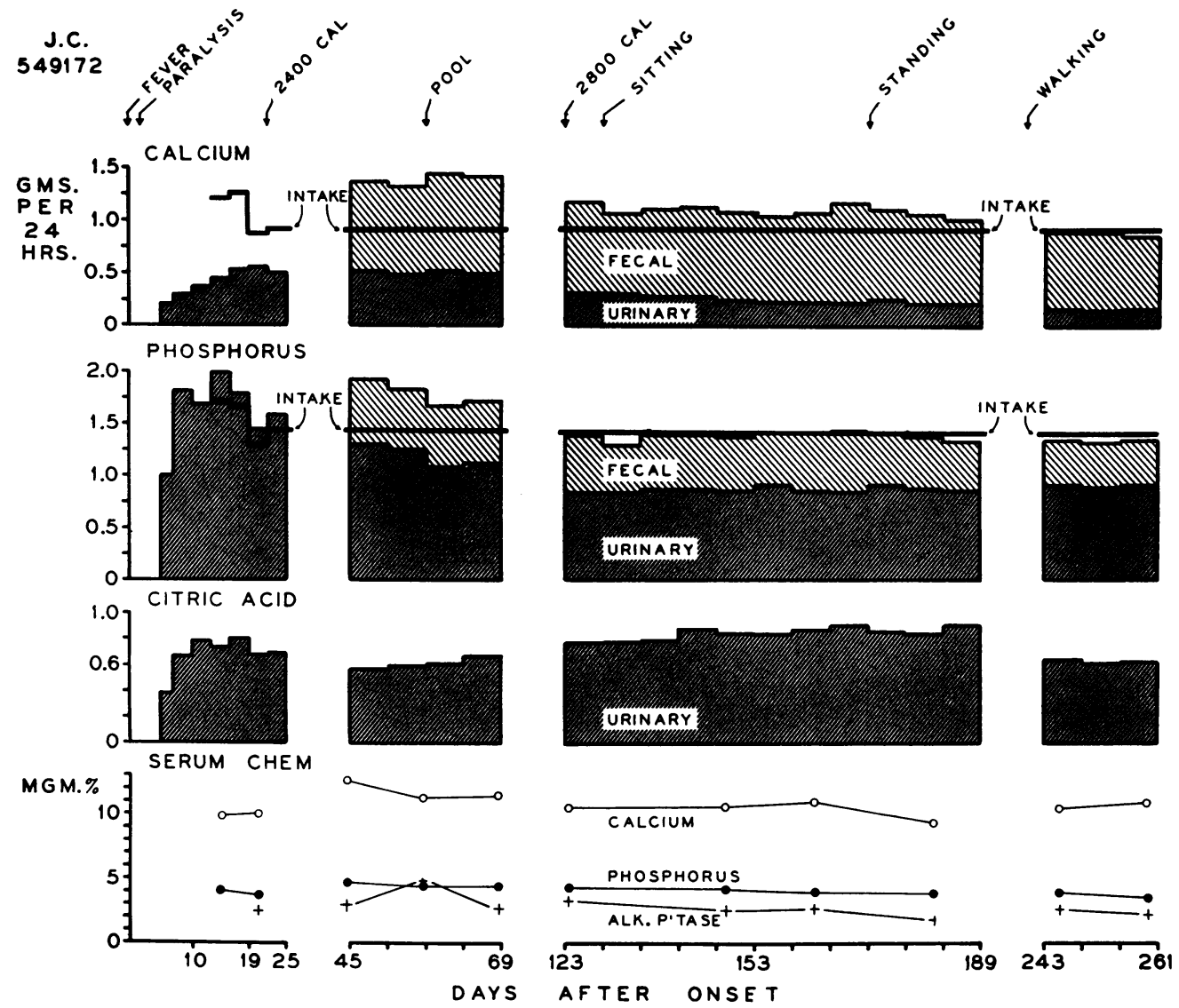

Fig. 4. Calcium and Phosphorus Balances, Urinary Citric Acid Excretion and Serum Calcium, Phosphorus and Alkaline Phosphatase during the First, Second, Fifth, Sixth and Ninth Months of Illness in a 39-Year-Old Male with Paralytic Acute ANTERior Poliomyelitis

TABLE I

Summary of data on calcium excretion and balance during convalescent phase of paralytic acute anterior poliomyelitis

\begin{tabular}{|c|c|c|c|c|c|c|c|}
\hline \multirow[b]{2}{*}{ Patient } & \multicolumn{2}{|c|}{$\begin{array}{l}\text { Maximal urinary } \\
\text { calcium } \\
\text { (6-day period) }\end{array}$} & \multirow{2}{*}{$\begin{array}{c}\text { Mean } \\
\text { urinary } \\
\text { calcium } \\
\text { 2nd-3rd } \\
\text { months }\end{array}$} & \multirow{2}{*}{$\begin{array}{c}\text { Duration } \\
\text { urinary } \\
\text { Ca over } \\
0.250 \mathrm{gm} .\end{array}$} & \multicolumn{2}{|c|}{$\begin{array}{c}\text { Maximal negative } \\
\text { balance }\end{array}$} & \multirow{2}{*}{$\begin{array}{c}\text { Mean } \\
\text { negative } \\
\text { balance } \\
\text { 2nd-3rd } \\
\text { months }\end{array}$} \\
\hline & Gm./day & $\begin{array}{l}\text { Week after } \\
\text { onset }\end{array}$ & & & Gm./day & $\begin{array}{c}\text { Week after } \\
\text { onset }\end{array}$ & \\
\hline & & & $g m . / d a y$ & months & & & $g m . / d a y$ \\
\hline D. Q. & 0.460 & 7 th & 0.401 & 3.5 & -0.420 & 6 th & -0.277 \\
\hline M. O'M. & 0.391 & 5 th & 0.354 & 3.5 & -0.471 & 10 th & -0.347 \\
\hline D. A. & 0.476 & 5 th & $(0.307)^{*}$ & 3 & -0.429 & 6 th & $(-0.124)^{*}$ \\
\hline J. C. & $\begin{array}{c}0.564 \\
(0.536)\end{array}$ & $\begin{array}{l}3 \mathrm{rd} \\
(6 \mathrm{th})\end{array}$ & 0.515 & 5 & -0.536 & 11 th & -0.434 \\
\hline R. W. & 0.661 & 5 th & $(0.477)^{*}$ & 6 & -0.572 & 6th & $(-0.428)^{*}$ \\
\hline F.S. & 0.674 & 6 th & 0.612 & 8 & $\begin{array}{l}(-0.663) \\
-0.669\end{array}$ & (7th) & -0.560 \\
\hline C. R. & 0.789 & (9th) $\ddagger$ & 0.687 & 9.5 & $\begin{array}{c}(-0.665) \\
-0.683\end{array}$ & $\begin{array}{l}\text { (9th) } \\
13 \text { th }\end{array}$ & -0.575 \\
\hline Mean & 0.574 & 5 th & $0.514 \dagger$ & 5.5 & -0.540 & 9 th & $-0.439 \dagger$ \\
\hline
\end{tabular}

* Procedure given during second month which reduced calcium excretion.

$\dagger$ Excluding the data of D. A. and R. W.

$\ddagger$ Study not started until eighth week. 


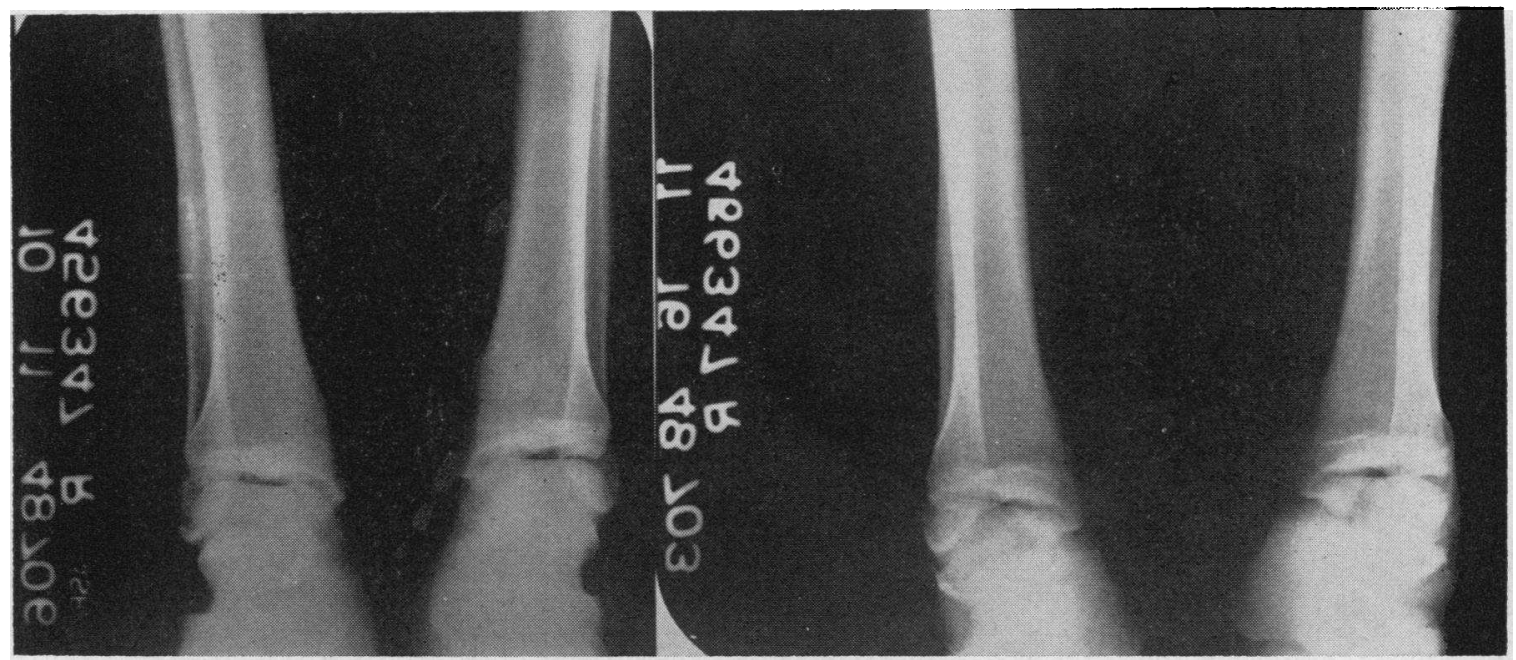

Fig. 5. Initial X-Ray Evidence of Development of Osteoporosis

On left: X-ray of tibiae of D.Q. taken during first month after onset of illness, showing essentially normal bone density.

On right: X-ray of tibiae of D.Q. taken two months after onset, showing sub-metaphyseal band of rarefaction.

ance, on intakes ranging from 1.35 to 1.66 grams daily, varied widely in time, from eight weeks to nine and one-half months after onset. Phosphorus generally began to be stored approximately two weeks before nitrogen, but in two patients, F.S. and C.R., who had very large calcium losses, phosphorus storage did not occur until two and one-half and five months after nitrogen balance was re- stored. The total measured phosphorus losses of the first four patients were 18.78, 11.38, 21.12 and $30.97 \mathrm{gm}$., the mean total loss being $20.56 \mathrm{gm}$.

Calculation of theoretical phosphorus balances based on the 14.7:1 ratio of nitrogen to phosphorus in muscle and on the $2.23: 1$ ratio of calcium to phosphorus in bone (21) revealed that phosphorus was excreted during the acute phase
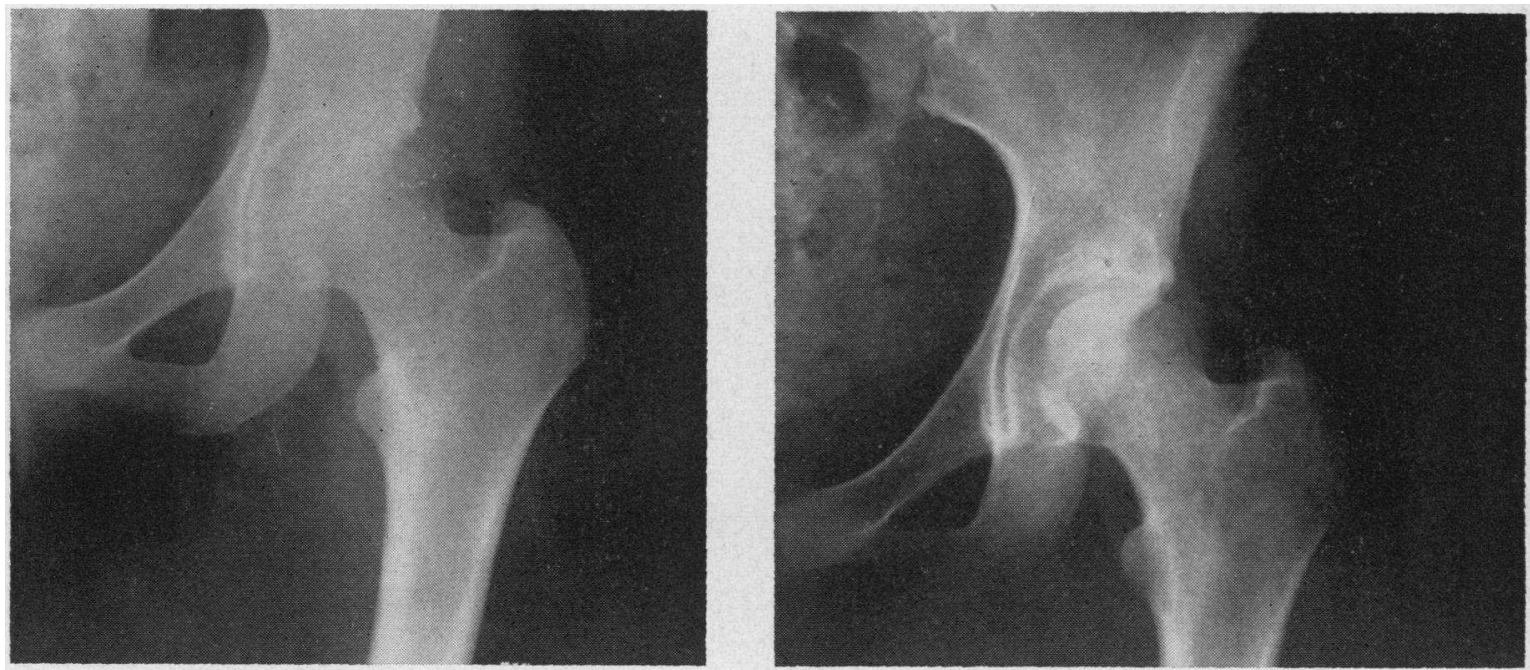

Fig. 6. Later X-Ray Evidences of Development of Osteoporosis

On left: X-ray of pelvis and femur of M.O'M. taken during first month after onset of illness, showing essentially normal bone density.

On right: X-ray of pelvis and femur of M.O'M. taken six months after onset, showing rarefaction of pubic ramus, acetabular fossa and neck and intertrochanteric area of femur. 


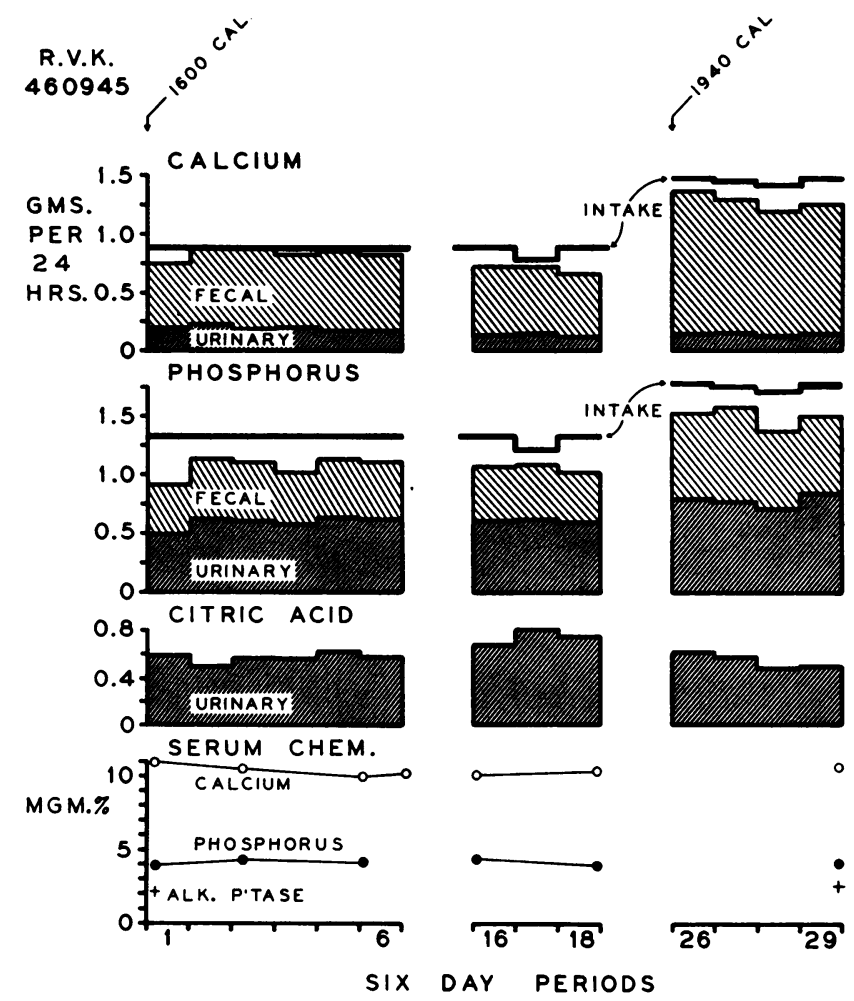

Fig. 7. Calcium and Phosphorus Balances, Urinary Citric Acid Excretion and Serum Calcium, Phosphorus and Alkaline Phosphatase during the 18th, 21st and 23rd Months after Onset of Illness in a 19-Year-Old Female with Paralytic Acute Anterior Poliomyelitis

of poliomyelitis in disproportionately greater amounts than nitrogen and calcium. The pattern was consistent from patient to patient. In the four studied early, for a three-day period between the 7 th and 10th days after onset actual or measured phosphorus excretion exceeded by 15 to 40 per cent the theoretical excretion based on calcium and nitrogen excretion. A long phase soon followed, averaging 39 days for the first five patients, when theoretical balances were more than 10 per cent more negative than actual phosphorus balances. This phase of retention, or less loss, of phosphorus relative to nitrogen and calcium occurred on the average between the 17 th and 56th days after onset and amounted to 15 to 20 per cent, or significantly more than could be accounted for by possible variations in diet. Following this phase, the measured and theoretical phosphorus balances agreed closely, generally within 5 per cent as related to intake. Within this close agreement, measured phosphorus balances from metabolic period to metabolic period were in every instance more positive than the theoretical.

\section{Factors influencing calcium solubility}

Among the principal known factors affecting calcium solubility in the urine are urine volume, $\mathrm{pH}$ and citric acid. Their role in relation to the problem of urinary tract stone formation has been discussed (22).

Citric acid is valuable because it forms with calcium a weakly ionized and very soluble calcium citrate complex. Formation of this complex evidently exerts a protective action in ambulatory patients in whom variations in calcium excretion induced by changes in diet are paralleled by proportional variations in citric acid excretion (22). However, when urinary calcium and phosphorus excretion increased during immobilization of normal subjects (2), urinary citric acid did not change 
TABLE II

Quantitative relationship between calcium loss and demonstrable osteoporosis in paralytic acute anterior poliomyelitis

\begin{tabular}{|c|c|c|c|c|c|c|c|c|c|}
\hline \multirow[b]{2}{*}{ Patient } & \multirow{2}{*}{$\begin{array}{l}\text { Pre- } \\
\text { illness } \\
\text { body } \\
\text { weight }\end{array}$} & \multirow{2}{*}{$\begin{array}{c}\text { Est. } \\
\text { total } \\
\text { body } \\
\text { Ca* }^{*}\end{array}$} & \multicolumn{3}{|c|}{$\begin{array}{l}\text { Initial long bone } \\
\text { osteoporosis }\end{array}$} & \multirow[b]{2}{*}{$\begin{array}{c}\text { Total } \\
\text { months } \\
\text { recumbent }\end{array}$} & \multicolumn{3}{|c|}{ Total calcium loss } \\
\hline & & & $\begin{array}{c}\text { Months } \\
\text { after } \\
\text { onset }\end{array}$ & $\begin{array}{c}\mathrm{Ca} \\
\text { loss }\end{array}$ & $\begin{array}{c}\mathrm{Ca} \\
\text { loss }\end{array}$ & & $\underset{\text { Dura- }}{\text { tion }}$ & Amount & $\%$ \\
\hline $\begin{array}{l}\text { D. Q. } \\
\text { M. O'M. } \\
\text { D. A. } \\
\text { J. C. } \\
\text { R. W. } \\
\text { F. S. }\end{array}$ & $\begin{array}{c}K_{8} . \\
61 \\
57 \\
89 \\
82 \\
68 \\
82\end{array}$ & $\begin{array}{c}\text { gm. } \\
1,098 \\
1,026 \\
1,602 \\
1,476 \\
1,224 \\
1,476\end{array}$ & $\begin{array}{l}2 \\
3 \\
3.5 \\
2.5 \\
3.5 \\
3\end{array}$ & $\begin{array}{c}g m . \\
18.0 \\
27.1 \\
15.4 \\
27.6 \\
36.0 \\
33.1\end{array}$ & $\begin{array}{c}\% \\
1.6 \\
2.6 \\
1.0 \\
1.9 \\
2.9 \\
2.2\end{array}$ & $\begin{array}{l}3.5 \\
3.5 \\
6 \\
7 \\
5 \\
8\end{array}$ & $\begin{array}{l}\text { mos. } \\
5 \\
5.5 \\
7 \\
7 \\
8 \\
8.5\end{array}$ & $\begin{array}{r}g m . \\
27.0 \\
43.0 \\
17.0 \\
54.9 \\
55.3 \\
95.5\end{array}$ & $\begin{array}{l}2.5 \\
4.2 \\
1.1 \\
3.7 \\
4.5 \\
6.5\end{array}$ \\
\hline $\begin{array}{l}\text { Mean of } 6 \\
\text { Patients }\end{array}$ & & & 3 & 26.2 & 2.0 & 5.5 & 7 & 48.8 & 3.8 \\
\hline C. R. & 67 & 1,206 & 2 & $(\mathbf{1 8 . 0}) \dagger$ & $(1.5) \dagger$ & 9 & 10 & 113.4 & 9.4 \\
\hline $\begin{array}{l}\text { Mean of } 7 \\
\text { Patients }\end{array}$ & & & & & & 6 & 7 & 58.0 & 4.6 \\
\hline
\end{tabular}

* See text and reference 20 for estimation as per cent of body weight.

$\dagger$ Including an estimate of calcium loss of first six weeks of illness based on rate of loss thereafter and taking into account the usual smaller losses during the first three weeks.

and urinary $\mathrm{pH}$ shifted slightly toward alkalinity, thus presenting conditions tending to favor precipitation of calcium phosphate. Urinary calcium in these subjects more than doubled without any compensatory rise in urinary citric acid.

In the patients immobilized with paralytic poliomyelitis a similar lack of compensatory rise in citric acid was evident, except in M.O'M., the only female who was studied during the early weeks. Her average urinary citric acid excretion during the first two weeks of illness was $0.505 \mathrm{gm}$. per day; during the fifth to seventh weeks when urinary calcium was highest $(0.329$ to $0.391 \mathrm{gm}$. per day) her citric acid nearly doubled and during the second and third months averaged $0.954 \mathrm{gm}$. per day (S.D. $= \pm 0.048$ ), a urinary citric acid/calcium ratio of $2.7: 1$. In the three males who were studied early, citric acid did not increase during the rise in urinary calcium excretion. For the six males studied during the convalescent phase, during the second and third months when mean urinary calcium was highest, 0.407 to $0.672 \mathrm{gm}$. per day, the urinary citric acid/calcium ratios ranged from $0.75: 1$ for R.W. to $1.31: 1$ for F.S., the mean ratio for the group being $1.11: 1$.

During acute and convalescent phases urinary $\mathrm{pH}$ remained consistently within the normal range and no trends in urinary volume were apparent.

\section{Blood chemistry}

The alterations in serum calcium and phosphorus during the first four months after onset are shown in Table III. With one exception, the mean serum calcium values were within normal limits for our laboratory, 9 to $11.5 \mathrm{mgm}$. per cent. In C.R., a 17-year-old boy, the mean was 11.9 with individual values ranging to $14.0 \mathrm{mgm}$. per cent. In J.C., a 39-year-old man, three of the nine serum calciums obtained during this phase were above $11.5 \mathrm{mgm}$. per cent. During the phase of hypercalcemia in these two patients urinary calcium averaged 0.687 and $0.490 \mathrm{gm}$. per day, respectively. After the first four months, with rare exception, serum calcium remained within normal limits.

In each patient a considerable number of values for serum phosphorus were higher than $4.5 \mathrm{mgm}$. per cent, the mean during the first four months exceeding this figure in four of the seven patients.

Serum alkaline phosphatase generally remained within a normal range of 2 to 4.5 units. Values tended to be low in D.Q and D.A. whose calcium losses were less than the other patients. In C.R., whose calcium loss was greatest, ten values during the fifth to ninth months (not shown in Table III) ranged from 4.2 to 7.1 , mean 5.5 units.

In view of the reported tendency for hypercalcemia to accentuate renal injury (4), it may be 
TABLE III

Summary of serum chemistry data during first four months after onset of poliomyelitis

\begin{tabular}{|c|c|c|c|c|c|c|c|c|c|c|}
\hline \multirow[b]{3}{*}{ Patient } & \multirow{2}{*}{\multicolumn{3}{|c|}{ Serum calcium }} & \multirow{2}{*}{\multicolumn{3}{|c|}{ Serum phosphorus }} & \multicolumn{4}{|c|}{ Serum alk. phosphatase } \\
\hline & & & & & & & \multirow[b]{2}{*}{ Mean } & \multirow[b]{2}{*}{ S.D. } & \multicolumn{2}{|c|}{ No. of det. } \\
\hline & Mean & S.D. & $\begin{array}{l}\text { No. of det. } \\
\text { over 11.5; } \\
\text { total no. }\end{array}$ & Mean & S.D. & $\begin{array}{c}\text { No. of det. } \\
\text { over } 5.0 / \\
\text { total no. }\end{array}$ & & & $\begin{array}{l}\text { Under } \\
2.0 / \\
\text { total no. }\end{array}$ & $\begin{array}{c}\text { Over } \\
4.5 / \\
\text { total no }\end{array}$ \\
\hline $\begin{array}{l}\text { D. Q. } \\
\text { M. O'M. } \\
\text { D. A. } \\
\text { J. C. } \\
\text { R. W. } \\
\text { F. S. } \\
\text { C. R. }\end{array}$ & $\begin{array}{c}m g m . \% \\
10.2 \\
10.3 \\
10.4 \\
11.0 \\
10.9 \\
11.2 \\
11.9\end{array}$ & $\begin{array}{r}m g m . \% \\
\pm 0.11 \\
\pm 0.52 \\
\pm 0.40 \\
\pm 0.83 \\
\pm 0.51 \\
\pm 0.95 \\
\pm 0.94\end{array}$ & $\begin{array}{l}0 / 8 \\
0 / 10 \\
0 / 12 \\
3 / 9 \\
1 / 8 \\
1 / 10 \\
4 / 7\end{array}$ & $\begin{array}{c}\text { mgm. \% } \\
4.4 \\
5.0 \\
4.4 \\
4.2 \\
4.9 \\
4.6 \\
5.1\end{array}$ & $\begin{array}{l}m g m . \% \\
\pm 0.26 \\
\pm 0.37 \\
\pm 0.30 \\
\pm 0.32 \\
\pm 0.43 \\
\pm 0.30 \\
\pm 0.21\end{array}$ & $\begin{array}{l}0 / 8 \\
4 / 10 \\
0 / 12 \\
0 / 9 \\
3 / 8 \\
1 / 10 \\
6 / 7\end{array}$ & $\begin{array}{c}m g m . \% \\
2.0 \\
3.1 \\
1.8 \\
2.9 \\
3.9 \\
4.1 \\
3.6\end{array}$ & $\begin{array}{r}m g m . \% \\
\pm 0.42 \\
\pm 0.66 \\
\pm 0.53 \\
\pm 0.88 \\
\pm 0.43 \\
\pm 0.90 \\
\pm 0.63\end{array}$ & $\begin{array}{l}2 / 6 \\
0 / 5 \\
7 / 9 \\
0 / 7 \\
0 / 7 \\
0 / 6 \\
0 / 5\end{array}$ & $\begin{array}{l}0 / 6 \\
0 / 5 \\
0 / 9 \\
1 / 7 \\
1 / 7 \\
3 / 6 \\
1 / 5\end{array}$ \\
\hline Mean & 10.8 & \pm 0.60 & & 4.7 & \pm 0.35 & & 3.1 & \pm 0.90 & & \\
\hline
\end{tabular}

noteworthy that blood urea nitrogen determinations performed bi-weekly were never elevated and no defect in urine concentration became apparent.

\section{B. Chronic Phase}

Two patients, J.W. and R.V.K. (Figure 7), were studied in the chronic phase (more than six months after onset of illness).

\section{Calcium}

When J.W. was first observed seven months after onset, urinary calcium was elevated, 0.301 gm. per day, and calcium balance was negative. By the following month urinary calcium had levelled to approximately $0.200 \mathrm{gm}$. per day and calcium balance was no longer negative; ambulation was unrelated as it was not begun until three and one-half months later. The time at which these indices returned to normal was within the range of the seven patients previously described. Thereafter, urinary calcium remained normal and calcium balance in equilibrium.

In R.V.K., studied between the 17th and 24th months after onset, urinary calcium remained well within normal limits and calcium balance was slightly positive. Her activity was limited to two hours daily in a wheel chair until the end of her studies.

Extensive and marked osteoporosis of pelvis and lower extremities in both patients at the time they were first observed indicated earlier extensive mineral loss which had gradually subsided, long prior to ambulation.

\section{Phosphorus}

Throughout these later months, phosphorus balance remained positive to the extent of 0.100 to $0.400 \mathrm{gm}$. daily. Urinary phosphorus was within normal limits. Theoretical phosphorus balances calculated from balances of nitrogen and calcium deviated less than 10 per cent from measured balances.

\section{Factors influencing calcium solubility}

Urinary citric acid excretion did not change during the chronic phase. Urinary citric acid/ calcium ratios were a high 4.0 and 3.6, respectively, in these two female patients. Urine volumes and urinary $\mathrm{pH}$ were not altered from the normal.

\section{Blood chemistry}

Serum calcium, phosphorus and alkaline phosphatase determinations in both patients were consistently normal.

\section{COMMENT}

Calcium loss in these paralytic patients was greater than has been previously documented for any other condition, including immobilization for fracture (vide infra). Immobilization or disuse appeared to be the major factor in the demineralization, although stress involving adrenal cortical hormone hypersecretion and the trophic influence of denervation may have been contributory.

\section{Influence of stress}

In our patients stress mediated through the adrenal cortex probably exerted only a minor in- 
fluence. Meagre evidence to date suggests that in poliomyelitis adrenal cortical hyperfunction continues for only a short period (1), while demineralization definitely continued for many months. Furthermore, from evidence in the literature, it is difficult to evaluate the effect of adrenal cortical stress on calcium excretion in man, particularly since in clinical states stress is often accompanied by immobilization. Courses of administration of ACTH (usually $100 \mathrm{mgm}$. daily) in ambulatory patients in whom calcium excretion has been studied $(23,24)$ have been brief, 5 to 12 days. Slight increases in urinary calcium were reported in five patients and virtually no change in twelve; fecal calcium excretion was apparently increased in five patients, but in each ACTH was given for 5 days or less. Augmented urinary calcium excretion was noted in only one of three patients receiving 100 to $200 \mathrm{mgm}$. of cortisone daily for as long as thirty days (25). That significant mineral losses may occur when cortisone is given over longer periods is strongly suggested by an increase in severity of osteoporosis of the spine in a patient with rheumatoid arthritis (26) and by persistent negative calcium balance in a similar patient (27). Only the short-term studies seem applicable to the present consideration, however, in view of probable limitation of stress in poliomyelitis to the first two weeks after onset; evidence that stress may exert an effect for a longer period in this disease has not yet been demonstrated. Studies to date have not consistently shown increased calcium excretion under short-term influence of adrenal cortical hypersecretion.

\section{Influence of denervation}

Denervation is usually accompanied by a considerable degree of disuse, but the latter may be minimized by passive motion or weight-bearing. A circumstance in our study in which effects of disuse apparently could be separated from those of denervation occurred in four patients who had severe paralysis of upper extremities. Only one (F.S.) showed demineralization of arm bones and that only to a mild extent; on the other hand, demineralization was uniformly present in femora and tibiae even though lower extremity paralysis was in several instances no more marked than upper. It is suggested that upper extremities, though severely paralyzed, rarely became demineralized because they were sufficiently used or moved.

That denervation per se probably does not cause extensive calcium loss is further supported by the observation by Abramson (28) on the effect of weight-bearing in two groups of paraplegics. Over a three-year period one group moved about only by wheel chair while the other walked with braces and crutches for an average of one hour daily. Twenty-five of the thirty non-ambulatory paraplegics showed osteoporosis of the pelvis and legs, whereas only one of the eight who walked with similar injury to the spinal cord showed bone rarefaction and that to only a mild degree.

Although these observations indicate that denervation could account for little, if any, of the extensive calcium loss in our patients, they are too limited to be conclusive. Recent study of urinary calcium excretion in poliomyelitis by Plum and Dunning $(29,30)$ showed hypercalciuria during early weeks in patients with bulbar or high spinal involvement but without extensive trunk or lower extremity paralysis, and these investigators have discussed (30) the possible role of neural factors in calcium loss. In their studies, an initial pattern was noted of gradual rise of urinary calcium over a period of several weeks, similar to that seen in the present study, indicating that movements of calcium are sluggish, apparently regardless of cause.

\section{Influence of immobilization}

Changes noted in this study of poliomyelitis are strikingly similar to those observed in other diseases in which immobilization has played an important role. The changes may be compared with those noted on immobilization of a 14-year-old boy following fracture of a femur treated with open reduction and plate (3), of a thirty-five-yearold women after fusion of an ankle (31), of two cases of Paget's following fracture (32), and of thirteen patients with prolonged dysfunction of a leg, nine of whom were tuberculous (33). The detailed study by Howard, Parson, and Bigham (5) of seventeen male patients immobilized with complete leg and partial body casts for fracture or osteotomy was extensive enough to outline a pattern of calcium loss. In this study, urinary calcium gradually rose during the first month to a 
high plateau level, averaging $0.510 \mathrm{gm}$. per day, which was maintained for sixty to one-hundred days; urinary calcium began to fall shortly before ambulation was instituted.

More direct evidence of the effects of immobilization per se was afforded by the study by Deitrick, Whedon, and Shorr (2) of normal healthy men with no previous bone disease. For six to seven weeks four subjects were immobilized (in plaster) to a degree approaching that of a patient such as D.Q. with extensive paralysis of the legs. While the subjects' dietary intake was kept constant, urinary calcium excretion increased gradually until at the fourth to fifth week it reached a peak, averaging $0.342 \mathrm{gm}$. per day, which was maintained for the remainder of the immobilization. Negative calcium balances were also of considerable magnitude. Maximal urinary calcium excretion in the fracture series was approximately 50 per cent greater and in the poliomyelitis patients was 67 per cent greater than in the immobilized normal subjects. The pattern of loss, however, was almost identical in the three groups, in which immobilization was an outstanding feature.

In the present group of patients, all of whom were extensively paralyzed, magnitude and particularly duration of calcium loss were in proportion to the degree of paralysis and to the degree and duration of immobilization, as is evident from inspection of the two summarizing tables (Tables I and II). In partial contrast to this observation, the study of urinary calcium excretion by Plum and Dunning $(29,30)$ of twenty-three patients with a wide variety of paralytic involvement due to poliomyelitis revealed little relationship between intensity of hypercalciuria and the site and degree of paralysis. Duration of hypercalciuria, however, was proportional to the degree of paralysis and to the amount of resulting immobilization.

\section{Mode of action of immobilization}

In the absence of weight-bearing, the skeleton is not exposed to stresses and strains that are thought to stimulate formation of bone in the interlacing arch-like patterns of cancellous trabeculae in long bones. Both absence of weight-bearing and muscle paralysis tend to reduce muscle-tendon pull on periosteal surfaces and so diminish the stimuli accentuating bone formation over bone resorption.
Abramson's study (28) of paraplegics seems to indicate that absence of skeletal weight-bearing is the more important factor since weight-bearing prevented osteoporosis of pelvis and lower extremities of completely paralyzed ambulatory patients.

The fundamental mechanism by which immobilization permits calcium loss is presumed to be decreased bone formation, with bone resorption continuing at a normal rate, rather than an increased bone resorption such as might be caused by hypersecretion of parathyroid hormone. The tendency to elevation of serum phosphorus during the course of the demineralization seems to exclude the possibility that the parathyroid glands were exerting an abnormal influence.

\section{Possible effects of circulatory changes}

Effects on mineral loss of possible changes in circulation to extremities and to bone during immobilization or following neurological injury are difficult to assess. Hyperemic circulatory changes have been reported to improve bone growth, as following sympathectomy (34) and in long standing arteriovenous fistulae (35), and to accelerate fracture healing as in experimental venous ligation (36). A conflicting view (37) has been expressed, however, that decreased blood supply results in increased density of bone and hyperemia leads to skeletal demineralization. It is not known whether changes in bone circulation occur during the paralytic stages of poliomyelitis, and, if so, what kind.

\section{Relationship of calcium loss to development of demonstrable osteoporosis}

The principal consequence of the large mineral loss was the development of bone rarefaction or osteoporosis. The important features were localization of its initial evidences in the ends of the long bones of the lower extremities, its appearance as early as three months after onset and the rather small calcium loss in relation to total body calcium, 2.0 per cent. It has been suggested that if non-paralyzed areas were excluded from the estimation of total body calcium used in this calculation, on the assumption that calcium loss and osteoporosis would develop only in paralyzed areas, this would increase the percentage figure 
of calcium loss before osteoporosis could be diagnosed by X-ray. Although this is true, the average figure would be raised relatively little since in this group of patients only the skull, ribs and in two instances the upper extremities could be considered unparalyzed.

The sharp band of rarefaction in the sub-metaphyseal area of the distal tibiae of three patients indicated extremely rapid demineralization in a location where bone turnover is normally particularly active. As mineral losses continued, rarefaction became apparent in the pelvis and, in one instance, in the humerus of an extremely paralyzed upper extremity. No evidence of demineralization in the spine appeared although total calcium losses ranged as high as 9.4 per cent. That early stages of demineralization were present in this area is suggested by observation of other patients with poliomyelitic paralysis in whom demineralization of the spine was detected after approximately one year. Since these patients were not on metabolic study, no accurate estimate can be made of the percentage loss of calcium necessary for obvious changes in this area. By comparison with losses of the metabolic group, however, it may be supposed that demonstration of osteoporosis of the spine requires calcium losses of more than 10 per cent. The figure may actually be much higher because of the difficulty of radiological interpretation of the spine due to the fine architecture of the vertebrae and interference by varied pattern of overlying bowel shadows.

\section{Urinary tract calculi formation as a potentially serious consequence of immobilization}

The high incidence of urinary tract calculi during immobilizing conditions is well known $(5,38$ 43) and is documented in Freeman's series (44) of 700 patients with spinal cord injury as 23 to 35 per cent. Certain factors which favor the precipitation of calcium phosphate in the urinary tract were shown to be present during the immobilization of normal men (2). These were excessive excretion of phosphorus as well as calcium, slight alkaline shift of $\mathrm{pH}$ and a failure of urinary citric acid to rise compensatorily with calcium as would be expected in ambulatory individuals. In the present study similar factors were evident in that urinary calcium and phosphorus were consider- ably increased and in the six male patients urinary citric acid failed to rise. There were no significant changes in urinary $\mathrm{pH}$ or volume. In the single female patient, increase in urinary calcium was accompanied by marked increase in urinary citric acid, a change which would aid in keeping calcium and phosphorus soluble. The increase in urinary citric acid in this patient is unexplained; it apparently was not related to the increase normally occurring in women during the menstrual cycle, presumably under the influence of estrogenic hormone $(45,46)$, since this patient had no vaginal bleeding during her hospitalization and no evidence of ovarian cyclic activity in vaginal smears.

In the patients here reported, no calculus developed, and the search for crystals and red blood cells in the urine was negative. Possibly calculi did not form because no other factors conducive to their formation were present. Urinary volumes were not permitted to fall to low levels. Except for brief intervals in two patients, infection, which would have reduced citric acid levels, did not occur; necessity for bacteria or a foreign body as a nucleus for precipitation of salts in the urinary tract has been emphasized (47) in the pathogenesis of nephrolithiasis. Obstruction or stasis $(6,7)$ presumably by kinking of a ureter, which has also been noted as factor, may have been prevented by frequent changes in position and movement brought about by physical therapy.

Another potential consequence to large mineral losses is renal injury occurring in conjunction with hypercalcemia (4), with attendant damage to renal tubules, albuminuria and reduced ability to concentrate urine. Evidence of impaired renal function was not detected in the present study.

\section{Serum calcium and alkaline phosphatase}

Hypercalcemia (serum calcium >11.5 mgm. per cent) was noted at some time during the course of these observations in four of the seven patients. In two of the four, however, elevation occurred in only a single determination. No relation was found between age of the patient and occurrence of hypercalcemia. Correlation was highly significant, however, for the whole group between mean serum calcium values and total calcium loss (corr. coeff. $=+0.809$ ), maximum 
negative calcium balance $(+0.809)$ and maximal urinary calcium over a six-day period $(+0.823)$.

Although serum alkaline phosphatase values generally remained within normal limits, they tended to be low in the two patients with the smallest total calcium losses, and some elevated values were noted in the two patients with the greatest losses. Ambulation was not a factor, since it was not begun until after these alkaline phosphatase changes had developed.

\section{Possible significance of changes in phosphorus excretion}

Changes in phosphorus excretion in relation to calcium and nitrogen were of unusual interest because of the high concentration of phosphorus in nervous tissue (48). Calculations of expected phosphorus excretion on the basis of the ratios of this element to $\mathrm{N}$ in muscle and $\mathrm{Ca}$ in bone indicated a disproportionate actual loss of phosphorus by 15 to 40 per cent between the seventh and tenth days and a relative retention over the succeeding six weeks. These changes paralleled closely with slight delay pathological events in the neurons of the spinal cord and brain $(49,50)$. Maximum destruction of motor nerve cells is complete within the first 3 to 6 days; thereafter, the proportion of normal motor neurons increases and of abnormal motor neurons decreases gradually for between four and six weeks, indicating recovery of abnormal cells. It seems not unlikely from consideration of quantitative relationships that early excess phosphorus excretion could have come mainly from destroyed or damaged nervous tissue and that later retention represented storage in recovering motor neurons. Abundance of phosphorus in other tissues, however, makes it difficult to exclude the possibility of influence of other factors in the movement of phosphorus.

\section{Influence of ambulation}

In view of the apparent relationship of immobilization to mineral loss in this and in preceding studies, the data were surveyed for evidence of an effect on calcium in the opposite direction by ambulation. Decreases in the excretion of calcium occurred during the later convalescent months, but they could be at most only partially ascribed to increased activity and ambulation, since these de- creases began uniformly prior to standing and walking; this apparently spontaneous decline in mineral loss suggested the possibility that there were stores of readily available calcium which were beginning to be depleted and that the remaining calcium in the skeleton was more tightly bound. With the beginning of ambulation, calcium excretion continued to decline gradually without evidence of more rapid fall. In other studies some influence of exertion on calcium excretion has been noted. Heavy resistance exercises reduced calcium loss in one of two patients with rheumatoid arthritis (51). A definite reductive influence of ambulation on excessive mineral loss was seen in the recovery phase of the immobilization study of normal men (2) in which ambulation was rapid, but in this study also return of calcium excretion to control levels was sluggish. It can only be concluded in the present study that a moderating effect on calcium of increased activity and ambulation, though possible, was not visible.

The question may be raised that if ambulation had been started earlier and allowed to proceed rapidly, it might have had an evident effect on calcium excretion. Ambulation was generally delayed because muscle recovery had not yet progressed to the point at which it could be expected to provide effective support of the skeleton and effective motility. Actually, some of the data suggested the possibility that too early ambulation might be harmful; brief but definite increases in urinary phosphorus and creatine were noted in the few instances in which ambulation was attempted abruptly. Others have observed increases in urinary calcium on early weight-bearing (52), although such changes were not evident in the present study. Finally, careful clinicians warn against too early ambulation $(53,54)$; premature weight-bearing apparently does not hasten the return of muscle power but may retard it and lead to harmful muscle substitution. When the patient has extensive paralysis, to minimize demineralization measures other than early ambulation evidently must be sought.

\section{SUMMARY}

This second paper of a series describing alterations in metabolism in paralytic acute anterior 
poliomyelitis outlined changes in calcium and phosphorus. Data were based on studies over six to nine months each of nine extensively paralyzed patients. Four were studied during the acute and convalescent phases of the disease, three during the convalescent phase only and two during the chronic phase. Calcium and phosphorus data presented in this paper were limited to those obtained during the administration of standard therapy, with the view of outlining the natural course of the disease with respect to these elements. Principal findings were as follows:

1. Progressive increase in calcium excretion was noted, primarily in the urinary component. Urinary calcium reached high levels at the fifth week after onset of illness which were sustained in plateau fashion for many months. Maximal urinary calcium excretion averaged $0.572 \mathrm{gm}$. per day; mean maximal negative calcium balance was $-0.540 \mathrm{gm}$. per day (constant calcium intake $0.920 \mathrm{gm}$. per day). Calcium balance remained negative for an average of seven months, mean total calcium loss being $58 \mathrm{gm}$.

2. The extensive calcium loss seemed to be related principally to the extreme degree of immobilization, an important aspect of which presumably was the lack of skeletal weight-bearing. Possible additional influences on calcium loss of denervation per se, of altered circulation to bone, and of stress mediated through the adrenal cortex were discussed.

3. The quantitative relationship was explored between total calcium loss and development of demonstrable osteoporosis, which initially appeared on the average three months after onset near joints of the long bones in the lower extremities. Average total calcium loss was 2.0 per cent of the estimated total body calcium at the time osteoporosis was initially detectable.

4. Increases in urinary excretion of calcium and phosphorus accompanied by little change in urinary volume, $\mathrm{pH}$ and citric acid excretion provided a suitable setting for urinary tract calculus formation in the male patients. In the single female patient studied during acute and convalescent phases, urinary citric acid excretion increased markedly, an event which would favor solubility of the increased amounts of mineral in the urine.
5. Serum calcium tended to rise in four of the seven patients studied during acute and convalescent phases; levels of serum calcium were directly related to degree of calcium loss.

6. Phosphorus excretion increased rapidly after onset reaching a peak on the 14th day, approximately three weeks prior to the time of maximal output of calcium. Calculation of theoretical phosphorus balances based on nitrogen and calcium balances indicated a disproportionate actual phosphorus loss during the second week and relative retention over the succeeding six weeks; the time parallel between these alterations and the pathological changes in phosphorus-rich nerve tissue was noted.

7. Observations during the chronic phase of paralytic poliomyelitis revealed essentially normal findings with respect to calcium and phosphorus excretion and blood levels.

8. Ambulation was not observed to exert a definite moderating influence on mineral loss. Modest evidence supported the suggestion of hazard in too early ambulation.

\section{ACKNOWLEDGMENT}

The authors wish to express their deep appreciation to H. H. Taussky, whose laboratory carried out the analyses of urinary citric acid in these studies. We are grateful to Dr. John Evans, Radiologist-in-Chief of the New York Hospital-Cornell Medical Center, for his interpretation of the bone $\mathrm{X}$-ray films.

\section{REFERENCES}

1. Whedon, G. D., and Shorr, E., Metabolic studies in paralytic acute anterior poliomyelitis. I. Alterations in nitrogen and creatine metabolism. J. Clin. Invest., 1957, 36, 942.

2. Deitrick, J. E., Whedon, G. D., and Shorr, E., Effects of immobilization upon various metabolic and physiologic functions of normal men. Am. J. Med., 1948, 4, 3.

3. Albright, F., Burnett, C. H., Cope, O., and Parson, W., Acute atrophy of bone (osteoporosis) simulating hyperparathyroidism. J. Clin. Endocrinol., 1941, 1, 711.

4. Howard, J. E., Hypercalcemia and renal injury. (Edit.) Ann. Int. Med., 1942, 16, 176.

5. Howard, J. E., Parson, W., and Bigham, R. S., Jr., Studies in patients convalescent from fracture. III. The urinary excretion of calcium and phosphorus. Bull. Johns Hopkins Hosp., 1945, 77, 291.

6. Brady, L., and Wilson, W. J., Major urological 
surgery on poliomyelitic patients confined to respirators; discussion on etiology, prophylaxis against and treatment of calculi in recumbent patients. J. Urol., 1948, 60, 381.

7. Creevy, C. D., and Tichy, F. Y., Etiology and treatment of urinary lithiasis in severe poliomyelitis. Arch. Neurol. \& Psychiat., 1952, 68, 539.

8. Snapper, I., Osteoporosis. M. Clin. North America, 1952, 36, 847.

9. Levin, S., Medical treatment in poliomyelitis. Am. J. Phys. Med., 1952, 31, 260.

10. Baker, A. B., Poliomyelitis. XI. Treatment. Neurology, 1954, 4, 379.

11. Whedon, G. D., Calcium loss in paralytic poliomyelitis and its quantitative relationship to the development of demonstrable osteoporosis. J. Clin. Invest., 1952, 31, 672.

12. Stinchfield, A. J., Reidy, J. A., and Barr, J. S., Prediction of unequal growth of the lower extremities in anterior poliomyelitis. J. Bone \& Joint Surg., 1949, 31-A, 478.

13. Gullickson, G., Jr., Olson, M., and Kottke, F. J., The effect of paralysis of one lower-extremity on bone growth. Arch. Phys. Med., 1950, 31, 392.

14. Ainslie, J. D., Stumpf, P. K., and Francis, T., Jr., Serum alkaline phosphatase in monkeys and man during poliomyelitis. Am. J. Hyg., 1951, 53, 58.

15. Taussky, H. H., and Shorr, E., A microcolorimetric method for the determination of citric acid. J. Biol. Chem., 1947, 169, 103.

16. Taussky, H. H., A microcolorimetric method for the determination of citric acid. II. A note on the substitution of ferrous sulfate as the reducing agent. J. Biol. Chem., 1949, 181, 195.

17. Bodansky, A., Phosphatase studies. II. Determination of serum phosphatase. Factors influencing the accuracy of the determination. J. Biol. Chem., 1933, 101, 93.

18. Bodansky, A., Determination of serum inorganic phosphate and of serum phosphatase. Am. J. Clin. Path., Tech. Suppl., 1937, 1, 51.

19. Woodward, H. Q., Acid and alkaline glycerophosphatase in tissue and serum. Cancer Research, 1942, 2, 497.

20. Shohl, A. T., Mineral Metabolism. New York, Reinhold Publishing Co., 1939, p. 19, Table 4 $(1.74 \%)$; p. 20 , Table $5(1.92 \%)$.

21. Reifenstein, E. C., Jr., Albright, F., and Wells, S. L., The accumulation, interpretation, and presentation of data pertaining to metabolic balances, notably those of calcium, phosphorus and nitrogen. J. Clin. Endocrinol., 1945, 5, 367.

22. Shorr, E., Almy, T. P., Sloan, M. H., Taussky, H. H., and Toscani, V., The relation between the urinary excretion of citric acid and calcium; its implications for urinary calcium stone formation. Science, 1942, 96, 587.

23. Mote, J. R., Ed., Proceedings of the First Clinical ACTH Conference, Chicago, Ill., October 21 and
22, 1949. Philadelphia-Toronto, The Blakiston Company, 1950.

24. Luft, R., Sjögren, B., and Li, C. H., Results of administration of adrenocorticotrophically active peptides (ACTH peptides) to a patient suffering from rheumatoid arthritis. Acta endocrinol., 1949, 3, 299.

25. Sprague, R. G., Power, M. H., Mason, H. L., Albert, A., Mathieson, D. R., Hench, P. S., Kendall, E. C., Slocumb, C. H., and Polley, H. F., Observations an the physiologic effects of cortisone and ACTH in man. Arch. Int. Med., 1950, 85, 199.

26. Demartini, F., Grokoest, A. W., and Ragan, C., Pathological fractures in patients with rheumatoid arthritis treated with cortisone. J. A. M. A., 1952, $149,750$.

27. Shorr, E., and Carter, A. C., The value of strontium as an adjuvant to calcium in the remineralization of the skeleton in osteoporosis in man in Conference on Metabolic Interrelations, 2nd Conf. Trans., p. 144 ; Cited by Whedon, G. D., Steroid hormones in osteoporosis in Hormones and the Aging Process, Engle, E. T., and Pincus, G., Eds., New York, Academic Press Inc., 1956, p. 233.

28. Abramson, A. S., Bone disturbances in injuries to the spinal cord and cauda equina (paraplegia); their prevention by ambulation. J. Bone \& Joint Surg., 1948, 30-A, 982.

29. Plum, F., and Dunning, M. F., Relationship between calciuria and the site and degree of paralysis in poliomyelitis. Clin. Research Proc., 1956, 4, 64.

30. Plum, F., and Dunning, M. F., Hypercalciuria following poliomyelitis; the relationship between mineral loss and the site and degree of paralysis. Arch. Int. Med., 1957, 99, 000.

31. Reifenstein, E. C., Jr., Individual Projects. Boston Group. [Continuation of the report: Atrophy of disuse. Trans. 1st Conference, Metabolic Aspects of Convalescence, Josiah Macy, Jr. Foundation, 3738, Sept. 1942] Trans. 2nd Conference, 1942, Dec., pps. 96-98.

32. Reifenstein, E. C., Jr., and Albright, F., Paget's disease: its pathologic physiology and the importance of this in the complications arising from fracture and immobilization. New England J. Med., 1944, 231, 343.

33. Ross, D., Disturbance of longitudinal growth associated with prolonged disability of the lower extremity. J. Bone \& Joint Surg., 1948, 30-A, 103.

34. Harris, R. I., and McDonald, J. L., The effect of lumbar sympathectomy upon the growth of legs paralyzed by anterior poliomyelitis. J. Bone \& Joint Surg., 1936, 18, 35.

35. Horton, B. T., Hemihypertrophy of extremities associated with congenital arteriovenous fistula. J. A. M. A., 1932, 98, 373.

36. Pearse, H. E., Jr., and Morton, J. J., The stimulation of bone growth by venous stasis. J. Bone \& Joint Surg., 1930, 12, 97. 
37. Jones, R. W., and Roberts, R. E., Calcification, decalcification and ossification. Brit. J. Surg., 1934, 21, 461.

38. Carlson, H. E., and Ockerblad, N. F., Stones of recumbency. South. M. J., 1940, 33, 582.

39. Flocks, R. H., Calcium phosphate renal lithiasis. J. Iowa M. Soc., 1945, 35, 321.

40. Joelson, J. J., Urinary calculi in recumbent patients. J. A. M. A., 1945, 129, 157.

41. Wilson, W. E., Renal colic and haematuria following recumbency. Brit. Med., J., 1931, 2, 101.

42. Leadbetter, W. F., and Engster, H. C., The problem of renal lithiasis in convalescent patients. J. Urol., 1945, 53, 269.

43. Boyd, M. L., The formation of renal calculi in bedridden patients. J. A. M. A., 1941, 116, 2245.

44. Freeman, L. W., The metabolism of calcium in patients with spinal cord injuries. Ann. Surg., 1949, 129, 177.

45. Shorr, E., Bernheim, A. R., and Taussky, H. H., The relation of urinary citric acid excretion to the menstrual cycle and the steroidal reproductive hormones. Science, 1942, 95, 606.

46. Shorr, E., The possible usefulness of estrogens and aluminum hydroxide gels in the management of renal stone. J. Urol., 1945, 53, 507.

47. Collica, I., New concept of the pathogenesis of urinary lithiasis. Am. J. Surg., 1948, 76, 424.

48. Shohl, A. T., Mineral Metabolism. New York, Reinhold Publishing Co., 1939, p. 182-3.

49. Bodian, D., The virus, the nerve cell, and paralysis. A study of experimental poliomyelitis in the spinal cord. Bull. Johns Hopkins Hosp., 1948, 83, 1.

50. Bodian, D., Poliomyelitis: pathologic anatomy. First International Poliomyelitis Conference, Philadelphia, J. B. Lippincott Co., 1949, p. 62.

51. Clark, W. S., Watkins, A. L., Tonning, H., and Bauer, W., The effects of resistance exercises on the nitrogen, phosphorus, and calcium metabolism of patients with rheumatoid arthritis. J. Clin. Invest., 1954, 33, 505.

52. Plum, F., and Dunning, M. F., Personal communication.

53. Green, W., Importance of rest in the treatment of early convalescent poliomyelitis. Am. J. Dis. Child., 1952, 83, 4.

54. Bennett, R. L., Resumption of activity following poliomyelitis. J. M. A. Georgia, 1954, 43, 706. 